\title{
Differential contribution of right and left amygdala to affective information processing
}

\author{
Hans J. Markowitsch* \\ Physiological Psychology, University of Bielefeld, \\ D-33501 Bielefeld, Germany
}

\begin{abstract}
Evidence for a differential involvement of the human left and right amygdala in emotional and cognitive behaviour is reviewed, with a particular emphasis on functional imaging results and case reports on patients with amygdalar damage. The available evidence allows one to conclude that there is definitely a hemisphere specific processing difference between the left and right amygdala. However, between studies the direction of the asymmetry is partly incongruent. In spite of this, the following tentative proposals are made: the left amygdala is more closely related to affective information encoding with a higher affinity to language and to detailed feature extraction, and the right amygdala to affective information retrieval with a higher affinity to pictorial or image-related material. Furthermore, the right amygdala may be more strongly engaged than the left one in a fast, shallow or gross analysis of affect-related information.
\end{abstract}

Keywords: Memory block, emotion, encoding, retrieval, fear, lateralisation

\section{The amygdala: interface between affect and memory}

One of the major differences between the brains of animals and humans is the extensive functional lateralisation of the human brain. This has been known for cortical areas since the times of Broca [18] and Wernicke [127], but only recent neuropsychological $[44,82,121,123]$ and structural [105] and functional neuroradiological research $[1,88,106,114,117]$ demonstrated its extension to subcortical structures. One of the structures which is of particular attraction for studying hemispheric-specific functional differences, is the amygdala, a nodal point for processing and integrating affect-related information [28].

The amygdala is a complex nuclear agglomerate in the anterior portion of the temporal lobe $[24,58,95,104,112,116]$ (cf. Figs 1 and 2) which

*Correspondence to: Hans J. Markowitsch, Physiological Psychology, University of Bielefeld, P.O. Box 1001 31, D-33501 Bielefeld, Germany. Tel.: +49 521106 4487; Fax: +49 521106 6049; E-mail: hjmarkowitsch@uni-bielefeld.de. demonstrates major changes during evolution [30, 79]. This review attempts to shed light on the differential roles of the left and right amygdala in certain aspects of emotional and mnestic behaviour. The review will first introduce some more general results on patients and normal subjects with respect to involvements of the amygdala in the processing of emotions and in modulating memory functions. Thereafter, different roles of the left and right amygdala with respect to these functions will be discussed, followed by making some inferences from the data bases.

While focussing on the amygdala, I wish to emphasise that this structure (as is the case for almost all other brain structures) cannot act on its own, but is dependent on the rest of the brain and in particular on the widespread network of closely interacting structures from the brain stem to the neocortex [59]. Furthermore, in this review I will avoid commenting on established differential roles of the various amygdaloid nuclei (Figs 1 and 2), as most of the available evidence stems from animal research (see, e.g., $[29,89,101,102,104,122])$, and there are at best very, very sparse data on lateralised functions of the amygdala in animals $[2,26]$.

Originally the amygdala was seen as a central structure for processing emotions [11, 39, 47, 54, 83, 119], and indeed its complex biochemistry includes a major affinity to stress hormone involvement [33, 97]. Changes in amygdaloid metabolism and structure may result in impaired social judgement [7, 15] and fear processing $[8,17,23,56,99]$, and in psychiatric diseases $[1,13,31,32,65,90,111]$.

A main hypothesis says that the amygdala primarily processes fear, anger, and anxiety-related information, and is unimportant in processing positive (or even disgust-related) information $[5,6,8,23,94,119,124$, 130]. Many reports on patients with bilateral amygdala damage favour this hypothesis (summarised in [10]), but functional imaging data on normal subjects indicate an involvement in the analysis of positive stimuli (e.g., happy looking faces) as well [16, 42, 85, 106]. An example for such a report is the study of Hamann et al. [42], using positron emission tomography. They 

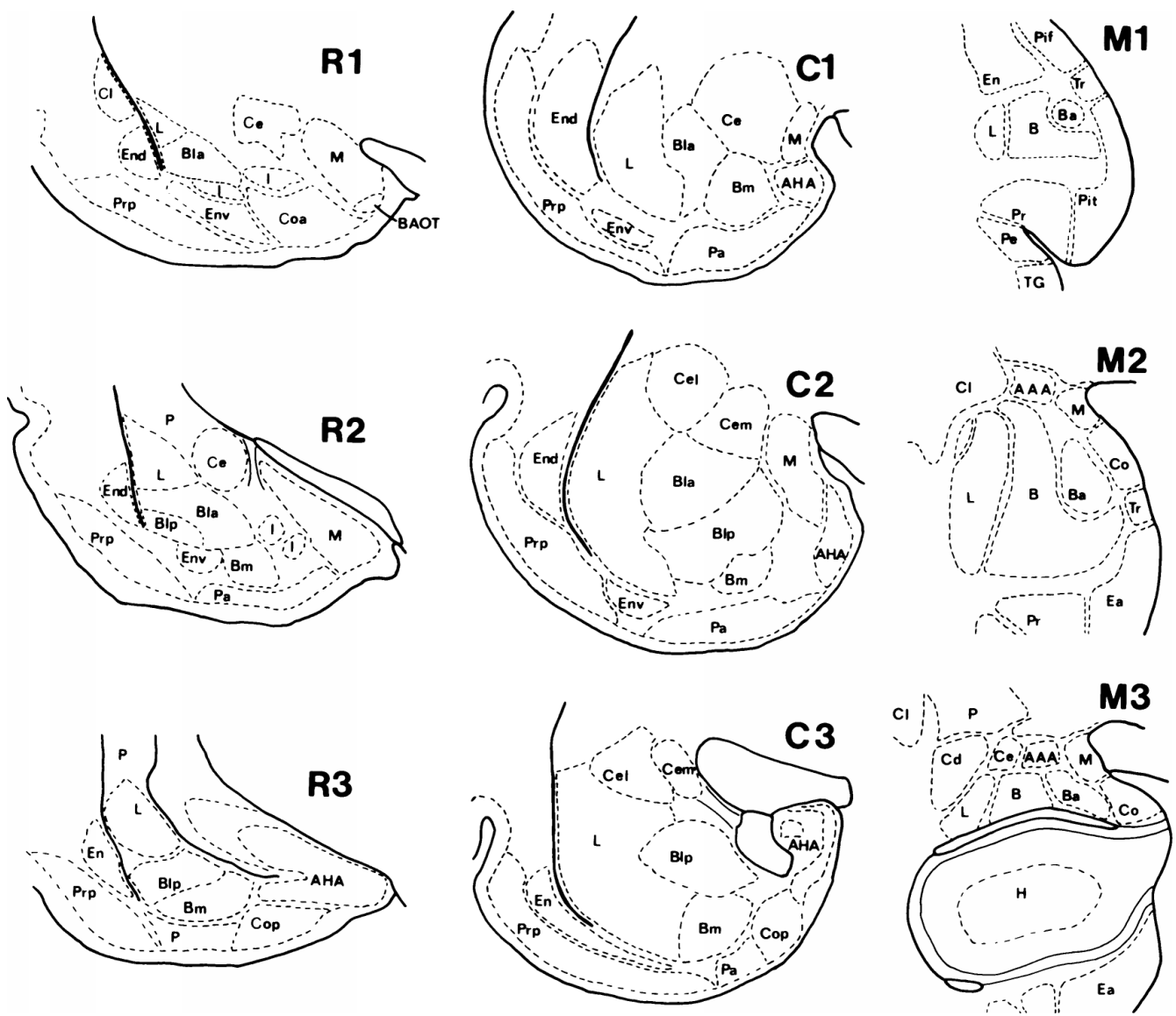

Fig. 1. Schematic illustrations of the amygdala of the rat (R), cat (C), and rhesus monkey (M) in coronal sections. For each of the three species, the amygdala is shown at an anterior (1), middle (2), and posterior (3) level. More detailed ways of subdividing some individual nuclei [magnocellular part and parvocellular part] have been omitted. Note that the drawings for the three species have not been made in the same scale. $\mathrm{AAA}=$ anterior amygdaloid area; $\mathrm{AHA}=$ amygdalo-hippocampal area; $\mathrm{B}=$ basal nucleus of the amygdala; $\mathrm{Ba}=$ basal accessory nucleus of the amygdala; BAOT = bed nucleus of the accessory olfactory tract; Bla = anterior division of the basolateral nucleus of the amygdala; $\mathrm{Blp}=$ posterior division of the basolateral nucleus of the amygdala; $\mathrm{Bm}=$ basomedial nucleus of the amygdala $; \mathrm{Cd}=$ caudate nucleus; $\mathrm{Ce}=$ central nucleus of the amygdala; $\mathrm{Cel}=$ lateral division of the central nucleus; $\mathrm{Cem}=$ medial division of the central nucleus; $\mathrm{Cl}=\mathrm{claustrum}$; $\mathrm{Co}=$ cortical nucleus of the amygdala Coa $=$ anterior division of the cortical nucleus; $\mathrm{Cop}=$ posterior division of the cortical nucleus; Ea $=$ entorhinal cortex, anterior part; En = endopiriform nucleus; End = dorsal division of the endopiriform nucleus; Env = ventral division of the endopiriform nucleus; $\mathrm{H}=$ hippocampal formation; $\mathrm{I}=$ intercalated masses; $\mathrm{L}=$ lateral nucleus of the amygdala; $\mathrm{M}=$ medial nucleus of the amygdala; $\mathrm{P}=$ putamen; $\mathrm{Pa}=$ periamygdaloid cortex $\mathrm{Pe}=$ perirhinal cortex $; \mathrm{Pif}=$ pririform cortex, frontal part Pit $=$ piriform cortex, temporal part; Pr = prorhinal cortex; Prp = prepiriform cortex; TG = temporal polar cortex; Tr = transition area. (After Fig. 1 of ref. 104; Copyright 1985 by the American Psychological Association. Reprinted with permission.)

found bilateral amygdala activation during encoding of pleasant stimuli. Isenberg et al. [50], who, however, did not use stimuli with a positive valence, observed a greater bilateral amygdala activation when normal subjects had to name words with threat valence than when they had to name words of neutral valence.

The Hamann et al. [42] report is an example of the currently increasing trend to combine the domains of emotion and memory, when studying the amygdala [22, 39, 59, 81, 104]. Adolphs et al. [3] described the amygdala as a mediator between the evaluation and experience of emotional events and their encoding and consolidation. Some years earlier, Sarter and Markowitsch [104] had proposed that it is the amygdala's role to charge cues so that mnemonic events of a specific emotional significance can be successfully searched within the appropriate neural nets and re-activated. And quite recently, McGaugh [80] emphasised that the amygdala is critically involved in memory consolidation by mediating the influences of epinephrine and glucocorticoids and regulating the actions of both the hippocampus and the striatum. (The hippocampus is 

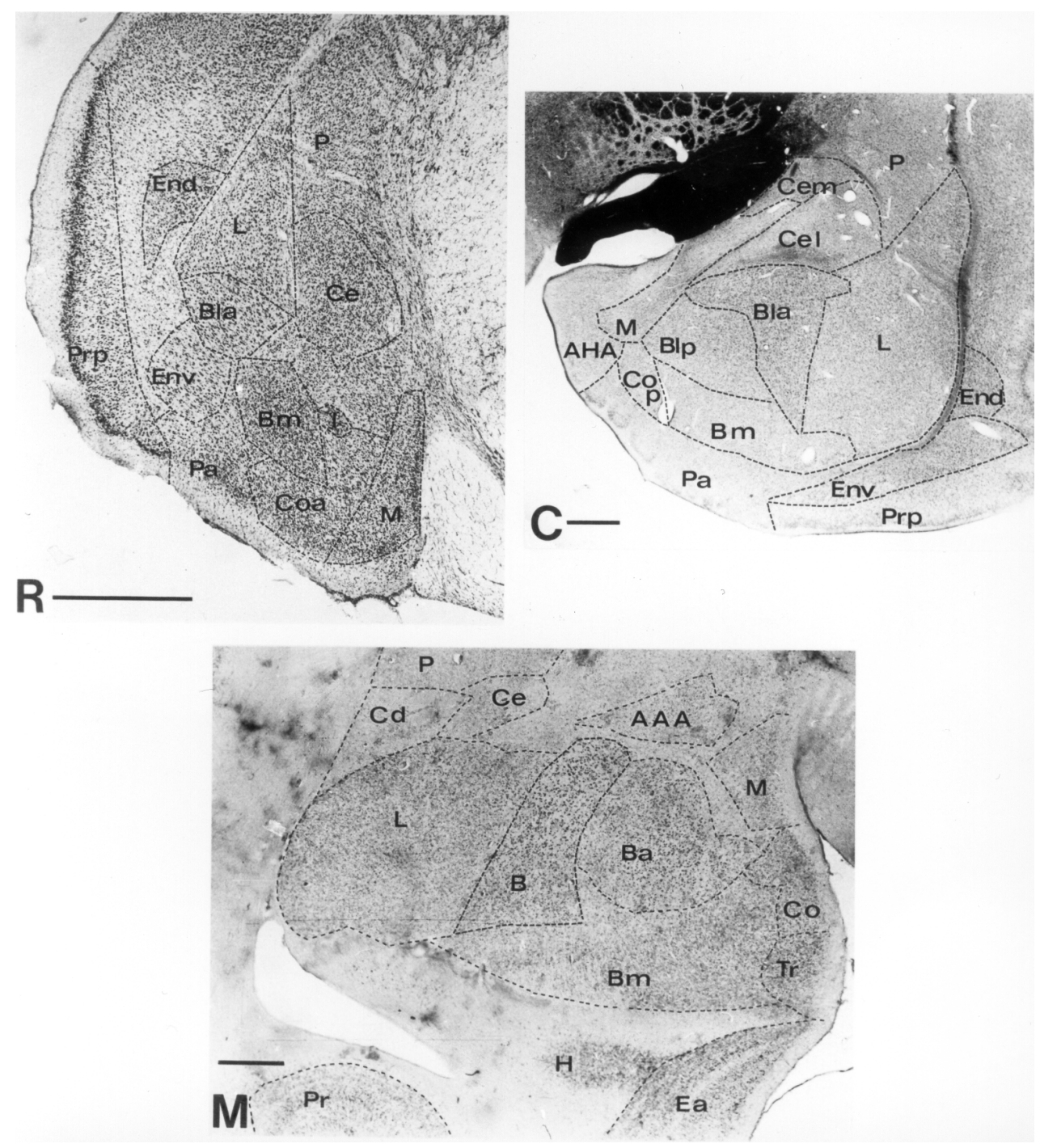

Fig. 2. Coronal section of the amygdala of the rat (R), cat (C), and monkey (M). The sections of the rat and monkey are from the left hemisphere; that of the cat is from the right one. The sections of the rat and monkey are stained with cresyl violet; that of the cat, with the Klüver-Barrera method. The scales represent $1 \mathrm{~mm}$. The abbreviations are given in the caption to Figure 1 . As long as there is still some debate on the identification and terminology of the basomedial nucleus of the monkey [also called basal nucleus, parvocellular part, or mediobasal nucleus], it is unclear whether this nucleus should be compared with the rat's and cat's basomedial nucleus or with their posterior basolateral nucleus. (After Fig. 2 of ref. 104; Copyright 1985 by the American Psychological Association. Reprinted with permission.)

said to be primarily engaged in episodic memory encoding and the striatum in that of procedural information $[68,69]$; the amygdala contains many adrenergic receptors and $\beta$-adrenergic receptor antagonists were found to block the memory-enhancing effects of emotional arousal.)

\subsection{Findings in patients}

Patients with amygdaloid damage become emotionally flat and are unable to differentiate between the significance of external stimuli or perceived information [21, 71]. Hamann et al. [43], however, opposed the idea that the amygdala is engaged in recognising emotions. They had two patients with complete bilateral amygdala damage who appeared unimpaired in recognising facial expression of emotion, including fear. Broks et al. [19] failed to confirm the findings of Hamann et al. [43], though they stressed that aetiology and extent of brain damage were very similar in both patient samples. They suggested differences 
in the testing procedures used to assess recognition of emotion, as a possible source for the discrepant data.

A recent multicentre study by Adolphs et al. [10] directly compared the recognition of facial emotion in nine patients with bilateral amygdala damage. While most of their subjects were impaired on several negative emotions including fear, there was still a range from severely impaired to essentially normal. For example, patient GT of Hamann et al. [43] again was largely unimpaired in this multicentre study though having extensive amygala and further brain damage. These observations are difficult to explain and the authors' only suggestion was that '... the subject may adopt alternate strategies that allow retrieval of knowledge about the emotion using anatomical routes other than the amygdala.' In light of the extensive brain damage in GT, it can be further speculated that especially after substantial brain damage there might be a release of inhibitory or blocking mechanisms which in less extensively damaged individuals still act suppressive. Evidence for this idea has been found both in animal studies [48, 49, 113] and on the human level [40, 51].

Phelps et al. [93] argued that it is more likely to be impaired arousal than impaired judgement of valences, which characterises patients with amygdala lesions. Their argument is supported by findings of Weniger et al. [126] who found significant deviations in arousal, but not in valence ratings of facial emotions in a patient during a state of likely hyperactivation of the right amygdala.

Other possible roles of the amygdalae are related to the processing of emotional responses and of information about reward [53,100], and - connected to the arousal functions proposed by Phelps et al. [93] - to joint attention [115].

In a study of two siblings with major amygdala degeneration resulting from Urbach-Wiethe disease (a rare metabolic disturbance with accumulation of a lipoprotein and hyalinisation, leading sometimes to selective amygdala degeneration), it was found that both had developed severe memory disturbances in verbal, visuo-spatial, and olfactory domains, most of which could be interpreted as being due to an inability to distinguish between emotionally significant and emotionally insignificant information [71]. A further investigation during which a story with an emotional content in its middle part had to be repeated after a delay, confirmed the inability of such patients to properly evaluate the significance of obtained information and therefore to remember significant details [21].
Related to this finding, Mori et al. [84] demonstrated that patients with probable Alzheimer's disease were unable to retrieve old episodic memories (about an emotionally significant earthquake in their city) when their amygdalar volume was reduced. While Phelps et al. [93] had suggested that the reduced processing of arousing stimuli will lead to improper emotional memory processing after amygdaloid damage, and Holland and Gallagher [46] had proposed that the amygdala is engaged in attentional (and relational) processes, the findings of Mori et al. [84] indicate that an amygdaloid activation may also be of relevance during retrieval of significant episodes.

\subsection{Functional imaging results in normal subjects}

Functional imaging studies in normal subjects have gained great popularity in the behavioural neurosciences of the last decade. This stems largely from the fact that they allow one to trace the processing of information in intact, non-brain damaged individuals and that they provide data on the whole brain. In particular, the technique of subtracting metabolic activity during one condition from activity during a related condition has been employed to gain insight into the normal brain's action and engagement during specific forms of information processing $[25,96]$. However, this technique has some disadvantages as well and has therefore been criticised or modified [20, 36, 37, 118, 129]. Especially, when inferences on asymmetric activations are made, the usual procedure is to identify the hemisphere with the greatest number of significantly activated voxels. This means that conclusions about asymmetry may be false because they rest on the comparison between two 'main effects.' (This statistical problem was pointed out by a reviewer of this paper.) Davidson and Irwin [28] suggested an alternative method which tests for the relevant group (or condition) $\times$ hemisphere interaction term; however, this apparently has not yet been done. Nevertheless, the alternative method is a more appropriate way of confidently identifying real hemisphere differences in activation. When evaluating the interpretations of functional imaging studies referred to below, this cautious note should therefore be kept in mind.

While it is generally emphasised that the amygdala is more closely involved in negative emotions such as fear $[8,56,99]$, there is still no straightforward evidence whether both amygdalae are primarily engaged in processing negative emotions, or whether there is a certain lateralisation [42]. A study with positron 
emission tomography (PET) on normal human volunteers given procaine (an anaesthetic) showed that procaine-induced fear compared to procaine-induced euphoria resulted in greater increases in left amygdalar cerebral blood flow [52]. Evidence for a lateralisation with respect to positive versus negative emotions would also be of importance in light of recent findings of a hemisphere-specific engagement in the retrieval of episodic-autobiographical as opposed to (neutral)semantic information $[34,62,66,70,72,77]$. Up to now results are inconclusive as, in the report of Fink et al. [34], both positive and negative old memories were combined, resulting in a primarily right hemispheric activation which included the amygdala. On the other hand, failure to ecphorise the own biography also failed to engage the amygdala at all [72]. (The term 'ecphory' describes the process by which retrieval cues interact with stored information so that an image or a representation of the information in question appears [120].)

Experimental studies confirmed the importance of the amygdalar nuclei both during encoding and storage of emotional information [22, 81]. And, in a recent functional imaging study, we found a selective activation of the right amygdala and uncus region during the retrieval of affect-related autobiographical old memories, as opposed to fictitious memories of a similar character [77]. Related to this finding was another report, based on positron emission tomography, in which a selective activation in the region of the amygdala was detected in a patient, who, probably due to sexual abuse as a child, failed to consciously memorise childhood information, but had some vague emotional memory about that time which she depicted in abstract drawings [78].

\section{Evidence for a differential functional involvement of the left and right amygdala}

Many reports indicate comparable structural changes $[13,111]$ or comparable functions of the two amygdalae, or suggest that damage to one amygdala can be compensated for by the other one $[9,15,35,57,84]$. There are, however, a few studies which have found a differential involvement of one amygdala in behavioural expression.

In a commentary, Tranel [119] pointed out that 'perhaps it will turn out that the two amygdalae are not functionally symmetric with regard to emotional processing' (p. 47). His hypothesis was reinforced by a comment of Young and Aggleton [130] who, however, emphasised that it might not be the processing of stimulus valence (as suggested by Tranel [119], Breiter et al. [16], and Whalen et al. [128]), but the appropriate implications of such information which is impaired after amygdaloid damage. This means that - in the view of Young and Aggleton [130] - amygdaloid damage may impair the possibility of recognising the signals or action implications of a certain aversive stimulus.

With respect to alterations in amygdaloid metabolism in psychiatric illness, there are two PET studies which indicate a hemisphere-specific involvement of the amygdala in depressed behaviour [1, 32]. Both reports provided, however, opposing results: While Drevets [32] found that depressed patients had higher blood flow rates in the left amygdala, Abercrombie et al. [1] observed them in the right amygdala. Abercrombie et al. [1] suggested that the difference in the two sets of results might be related to technical differences in scanning and to the homogeneity and more severe illness of the patients studied by Drevets et al. [32]. While these reports are not of help in elucidating possibly differing roles of the left and right amygdala, they indicate at least that it needs sophisticated designs and a careful selection of patients when testing possible consequences of psychic deviations on the brain. Drevets [32], in fact, discussed a number of points which are of direct relevance to the interpretation of image data in depressed subjects. Among them are medication effects, the clinical heterogeneity inherent within the depressive syndrome (e.g., anxiety, obsessive ruminations, psychomotor agitation, versus apathy and psychomotor slowing), and the heterogeneity with regard to etiology and pathology.

Most findings on a hemispheric-specific involvement of the two amygdalae come from reports in normal subjects. Paradiso and co-workers [92] studied cerebral blood flow changes in response to emotional valence determination for pleasant, unpleasant, and neutral stimuli. They found in 17 normal subjects that the evaluation of unpleasant visual stimuli activated (among other regions) the left amygdala. This activation not only held for fear-related, but for a wide range of unpleasant stimuli.

Studying regional cerebral blood flow changes in response to the presentation of faces with different emotional expressions, has provided a major basis for establishing a differential role of the left and right amygdala in cognitive information processing. Interesting results were obtained in a series of studies by Morris [85, 87, 88]. Morris et al. [85] found enhanced 
activity in the left amygdala of normal subjects during the processing of fearful faces. Also Breiter et al. [16] observed a higher activation of the left compared to the right amygdala during viewing of fearful faces and Ketter et al. [52] similarly reported a procaineinduced left hemispheric amygdaloid activation, correlating positively with fear. On the other hand, Morris et al. [87, 88] found a significant neural response in the right, but not the left, amygdala to masked presentations of a conditioned angry face. Combined, these findings suggest that unconscious (masked) processing is mediated more readily by the right, and conscious processing more readily by the left amygdala (among other structures). Alternatively, when taking into account related reports on the recognition of facial expression, which in patients with right, but not with left neocortical damage led to an impairment [4], it might be proposed that especially more superficial face processing is a matter of right-hemispheric structures.

These data are also in conformity with results emphasising the left hemisphere in detailed, analytic processing of faces and figures [55], and the right hemisphere in a more or-all-none global, immediate stimulus perception [45]. Krickl et al. [55] had presented figures and human faces to patients with damage to the right or left hemisphere. The stimuli were presented under three conditions: normal, sequential (1/3, 2/3, full picture) and fragmentary (faces only). Under the condition 'normal' the stimulus was shown for $0.3 \mathrm{~s}$ as a whole, under condition 'sequential' it was presented in three degrees of completeness, the first showing one third and the third the complete picture, and under condition 'fragmentary', only the upper third of the face was shown during learning, while for testing the complete face had to be identified among distractor items. The authors found a dissociation between side of brain damage and performance under sequential versus normal presentation. Similar to control subjects, patients with left hemispheric brain damage remembered previously seen stimuli better under normal ('global') presentation, while patients with right hemispheric brain damage were superior under partial or sequential presentation.

Henke et al. [45] studied the subliminal perception of human faces in normal subjects and found a right hemisphere advantage under conditions of very brief $(40 \mathrm{~ms})$, but repeated presentation. That processing in the left hemisphere is more analytic and in the right one is more global is also confirmed by fear conditioning, an in principal universal or general condition. Fear conditioning in humans was related to a heightened activation of the right amygdala [38]. Fear conditioning was accomplished by pairing visual snake stimuli with electric shock and measuring non-specific electrodermal fluctuations and regional cerebral blood flow changes (PET) [38]. In animals, Coleman-Mesches and McGaugh [26] similarly found that the right amygdala was more important to the expression of memory for aversively motivated training.

Using olfactory stimuli, Zald and Pardo [131] demonstrated with PET imaging that left amygdala blood flow was significantly correlated with subjective ratings of perceived aversiveness, indicating that the left amygdala is to a higher degree than the right one involved in hedonic or emotional processing of olfactory stimuli.

Cahill et al. [22] asked normal subjects to learn the contents of 12 emotionally arousing and 12 neutral film clips and measured their regional cerebral glucose metabolism during retrieval. They found that glucose metabolism in the right amygdala correlated significantly with the number of emotional but not neutral film clips remembered long-term under free recall conditions. Encoding of neutral information failed to activate either the left or right amygdala [12]; instead, the hippocampal region was found to be engaged in this process. It might be mentioned in this context that in the study of Hamann et al. [42], discussed above, both amygdalae were activated, while in that of Cahill et al. [22] significant increase was restricted to the right one only. (There is, however, no direct comparison possible, as one report was based $\mathrm{H}_{2}^{15} \mathrm{O}$ and the other on FDG-PET.) Furthermore, Hamann et al. [42] interpreted their findings as showing that the amygdala seems to modulate, through interactions with the hippocampus, the strength of conscious memory for emotional events, regardless of their valence.

Similarly to Cahill et al. [22], Fink et al. [34] observed a highly significant activation in the right anterior and medial temporal lobe regions during the recall of old autobiographic information (this information was usually of considerable emotionality). Vice versa, failure of recall of autobiographic episodes in psychogenic amnesia also failed to activate these right hemispheric regions (and instead activated more centrally and left hemispherically situated regions) [70].

Using PET, Hamann et al. [41] examined the neural systems engaged in positive and negative emotion and in emotional episodic memory. Viewing both positive (e.g., erotica) and negative (e.g., mutilation) emotional stimuli activated the left amygdala significantly in normal subjects, and memory encoding of positive 
Table 1

Results and hypotheses on the involvement of both or one amygdala in emotion and cognition

More general results and hypotheses:

- The amygdala is a mediator between the evaluation and experience of emotional events and their encoding and consolidation [3].

- It is the amygdala's role to charge cues so that mnemonic events of a specific emotional significance can be successfully searched within the appropriate neural networks and (re-)activated [104].

- The amygdala is important for all stages of information processing: during encoding [22] and storage [56] of information, and during its retrieval [34, 84].

- The amygdala is more strongly engaged in negative than in positive information processing $[5,6,8,23,94,119$, $124,130]$.

- The amygdala is involved in the processing of stimulus valency [16, 119, 128].

- The amygdala is engaged in arousal $[92,125]$ and attentive $[46]$ aspects of information processing.

- The amygdala is involved in processing information about reward [53, 100].

- The amygdala is central to the appropriate recognition of emotions [130].

Results and hypotheses emphasising a differential role of the left (as opposed to the right) amygdala:

- The left amygdala is engaged in hedonic or emotional processing of olfactory stimuli [131].

- The left amygdala is engaged especially in processing of fearful stimuli $[16,28,52,85]$.

- The left amygdala is engaged in processing both pleasant and aversive stimuli [41].

- The left amygdala is more active during generation of words with emotional meaning than during generation of neutral words [27].

- The left amygdala as opposed to the right one has a higher cerebral blood flow in depressed patients [32].

Results and hypotheses emphasising a differential role of the right (as opposed to the left) amygdala:

- The right amygdala as opposed to the left one has a higher cerebral blood flow in depressed patients [1].

- The right amygdala has an enhanced cerebral blood flow during masked stimulus presentation [87, 88].

- The right amygdala is engaged in the retrieval of emotional old memories [34, 98] and in remembering emotional information [21, 22].

The listed hypotheses are not mutually exclusive.

and negative pictures activated the amygdala bilaterally. Similarly to the results of Hamann et al. [41, 42], Crosson and co-workers [27], in a functional magnetic resonance imaging study with 17 normal strongly right-handed subjects, obtained evidence for an activation of the left amygdala during generation of emotionally evocative words, but not during generation of emotionally neutral words.

\section{Consequences for a differential role of the two amygdalae}

The results described above and related findings on hemisphere-specific processing in the region of the anterior temporal lobe [62,63], suggest a number of conclusions which will now be outlined. The summarised results and hypotheses of Table 1 give a rough guide to the bases of these conclusions.
Table 1 indicates that both the left and right amygdala are principally engaged in emotional processing and in linking emotional stimuli to memory. There is a prevalence for processing negative as opposed to positive stimuli, but this prevalence may be confounded with the salience of the respective stimuli. The amygdala also seems to be important for encoding and retrieval of information.

With respect to a differential involvement of the left and right amygdala, there are some partially inconsistent or even opposing results (e.g., with respect to the consequences of depression on amygdaloid activity). However, the right amygdala seems to be more engaged than the left one in the retrieval of emotional information and in a more shallow or crude general processing of information.

The following hypotheses are proposed: The left amygdala is particularly involved in the active process- 
ing of threatening and other emotional stimuli, particularly in their encoding [83, 104, 105, 106], but also in their retrieval $[27,41]$. The more frequently observed amygdalar engagement in negatively affective stimuli is reflected by the finding that the induction of a sad mood in normal subject leads to increases in cerebral blood flow in the left amygdala and to a decrease in the right one [106]. It may, however, also be related to the frequently greater salience of negative compared to positive emotional stimuli.

The right amygdala is mainly engaged in implicit processing of affective information and in the implicit (and to lesser degree also the explicit) retrieval of emotion-related information $[14,34,72,77,78,88$, 98, 110]. Especially the expected outcome of behavioural, arousal-evoking responses may be intensely modulated by the amygdalae with the right one probably engaging more in imagery-related, pictorial and fast or shallow, and the left one probably more in explicit, language-related or feature-extracting processes [109, 125]. For instance, the consciously reflected rating of olfactory stimuli engages the left amygdala [131], while conditioned fear reactions [38] or confrontation with traumatic events [98] activate the right one.

It is not unlikely that the two amygdalae (as well as surrounding cortical regions of the anterior temporal, the orbitofrontal and the cingulate cortex $[28,34,114,117])$ complement each other in the way they process information with the right-hemispheric structures being more strongly engaged in a gross, overall analysis and the left-hemispheric structures being engaged in a detailed, in-depth analysis. This hypothesis would also fit the assumption that an understanding of new incoming information needs a comparison with already existing information (done by the left amygdala and other structures), while the process of retrieval (information ecphory) more likely can occur on the basis of minor retrieval cues and may be done in a broader or less specific manner - and with the help of the right amygdala and surrounding regions.

The high receptor density of the amygdala for glucocorticoids, released in response to stress, points to the importance of - probably mainly the left amygdala - for (detailed) information encoding [61, 81, 97], and of the right one for information retrieval [34, 77], or, when there is a stress-induced memory block [64, 67, 91, 103], for failure of memory retrieval. Such blocking conditions may lead to major and lasting memory disorders $[73,74,75]$. While these ideas are still speculative, they can be tested both experimentally and by neuropsychological case studies.

The above-given hypotheses are multi-leveled or intermingled which, however, seems to be justified both by the available data and by the means and manner of information processing within the nervous system.

\section{Acknowledgements}

My research was supported by the German Research Council (DFG; grant Ma 795/24).

\section{References}

[1] H.C. Abercrombie, S.M. Schaefer, C.L. Larson, T.R. Oakes, K.A. Lindgren, J.E. Holden, S.B. Perlman, P.A. Turski, D.D. Krahn, R.M.B. Benca and R.J. Davidson, Metabolic rate in the right amygdala predicts negative affect in depressed patients, Neuroreport 9 (1998), 3301-3307.

[2] R.E. Adamec and H.D. Morgan, The effect of kindling of different nuclei in the left and right amygdala on anxiety in the rat, Physiology and Behavior 47 (1994), 567-574.

[3] R. Adolphs, L. Cahill, R. Schul and R. Babinsky, Impaired declarative memory for emotional material following bilateral amygdala damage in humans, Learning and Memory 4 (1997), 291-300.

[4] R. Adolphs, H. Damasio, D. Tranel and A.R. Damasio, Cortical systems for the recognition of emotion in facial expressions, Journal of Neuroscience 16 (1996), 7678-7687.

[5] R. Adolphs, J.A. Russell and D. Tranel, A role for the human amygdala in recognizing emotional arousal from unpleasant stimuli, Psychological Science 10 (1999), 167-171.

[6] R. Adolphs and D. Tranel, Preferences for visual stimuli following amygdala damage, Journal of Cognitive Neuroscience 11 (1999), 610-616.

[7] R. Adolphs, D. Tranel and A.R. Damasio, The human amygdala in social judgment, Nature 393 (1998), 470-474.

[8] R. Adolphs, D. Tranel, H. Damasio and A. Damasio, Impaired recognition of emotion in facial expressions following bilateral damage to the human amygdala, Nature $\mathbf{3 7 2}$ (1994), 669-672.

[9] R. Adolphs, D. Tranel, H. Damasio and A.R. Damasio, Fear and the human amygdala, Journal of Neuroscience $\mathbf{1 5}$ (1995), 5879-5891.

[10] R. Adolphs, D. Tranel, S. Hamann, A.W. Young, A.J. Calder, E.A. Phelps, A. Anderson, G.P. Lee and A.R. Damasio, Recognition of facial emotion in nine individuals with bilateral amygdala damage, Neuropsychologia 37 (1999), 11111117.

[11] J.P. Aggleton and M. Mishkin, The amygdala: Sensory gateway to the emotions, in: Emotion. Theory, Research, and Experience, Vol. 3 Biological Foundations of Emotion, R. Plutchik and H. Kellerman, eds, Academic Press, New York, 1986, pp. 281-299.

[12] M.T. Alkire, R.J. Haier, J.H. Fallon and L. Cahill, Hippocampal, but not amygdala at encoding correlates with long-term, free recall of nonemotional information, Proceedings of the National Academy of Sciences of the USA 95 (1998), 14506-14510. 
[13] L.L. Altshuler, G. Bartzokis, T. Grieder, J. Curran and J. Mintz, Amygdala enlargement in bipolar disorder and hippocampal reduction in schizophrenia: An MRI study demonstrating neuroanatomic specificity, Archives of General Psychiatry 55 (1998), 663-664

[14] M.M. Bianchin and C.W. Spanis, Involvement of the amygdala in explicit memories, Neurology 51 (1998), 1520.

[15] N. Birbaumer, W. Grodd, O. Diedrich, U. Klose, M. Erb, M. Lotze, F. Schneider, U. Weiss and H. Flor, fMRI reveals amygdala activation to human faces in social phobics, NeuroReport 9 (1998), 1223-1226.

[16] H.C. Breiter, N.L. Etcoff, P.J. Whalen, W.A. Kennedy, S.L. Rauch, R.L. Buckner, M.M. Strauss, S.E. Hyman and B.R. Rosen, Response and habituation of the human amygdala during visual processing of facial expression, Neuron 17 (1996), 875-887.

[17] H.C. Breiter and S.L. Rauch, Functional MRI and the study of OCD: From symptom provocation to cognitivebehavioral probes of cortico-striatal systems and the amygdala, Neuroimage Dec 4 (1996), S127-S138.

[18] P. Broca, Remarques sur le siège de la faculté du langage articulé: Suivies d'une observation d'aphémie (perte de la parole), Bulletin de la Societé Anatomique de Paris 366 (1861), 330-357.

[19] P. Broks, A.W. Young, E.J. Maratos, P.J. Coffey, A.J. Calder, C.L. Isaac, A.R. Mayes, J.R. Hodges, D. Montaldi, E. Cezayirli, N. Roberts and D. Hadley, Face processing impairments after encephalitis: amygdala damage and recognition of fear, Neuropsychologia 36 (1998), 59-70.

[20] R.L. Buckner, W. Koutstaal, D.L. Schacter, A.M. Dale, M. Rotte and B.R. Rosen, Functional-anatomic study of episodic retrieval. II. Selective averaging of event-related fMRI trials to test the retrieval success hypothesis, NeuroImage 7 (1998), 163-175.

[21] L. Cahill, R. Babinsky, H.J. Markowitsch and J.L. McGaugh, Involvement of the amygdaloid complex in emotional memory, Nature 377 (1995), 295-296.

[22] L. Cahill, R.J. Haier, J. Fallon, M. Alkire, C. Tang, D. Keator, J. Wu and J.L. McGaugh, Amygdala activity at encoding correlated with long-term, free recall of emotional information, Proceedings of the National Academy of Sciences of the USA 93 (1996), 8016-8021.

[23] A.J. Calder, A.W. Young, D. Rowland, D.I. Perrett, J.R. Hodges and N.L. Etcoff, Facial emotion recognition after bilateral amygdala damage: Differentially severe impairment of fear, Cognition and Neuropsychology 13 (1996), 699-745.

[24] M.D. Cassell, The amygdala: myth or monolith?, Trends in Neurosciences 21 (1998), 200-201.

[25] J. Chmielowska, R.C. Coghill, J.-M. Maisog, R.E. Carson, P. Herscovitch, M. Honda, R. Chen and M. Hallett, Positron emission tomography $\left[{ }^{15} \mathrm{O}\right]$ water studies with short interscan interval for single-subject and group analysis: Influence of background subtraction, Journal of Cerebral Blood Flow and Metabolism 18 (1998), 433-444.

[26] K. Coleman-Mesches and J.L. McGaugh, Differential involvement of the right and left amygdalae in expression of memory for aversively motivated training, Brain Research 670 (1995), 75-81.

[27] B. Crosson, K. Radonovich, J.R. Sadek, D. Gökcay, R.M. Bauer, I.S. Fischler, M.A. Cato, L. Maron, E.J. Auerbach, S.R. Browd and R.W. Briggs, Left-hemisphere processing of emotional connotation during word generation, NeuroReport 10 (1999), 2449-2455.
[28] R.J. Davidson and W. Irwin, The functional neuroanatomy of emotion and affective style, Trends in Cognitive Science 3 (1999), 11-21.

[29] M. Davis, Are different parts of the extended amygdala involved in fear versus anxiety?, Biological Psychiatry $\mathbf{4 4}$ (1998), 1239-1247.

[30] J.S. de Olmos, Amygdala, in: The Human Nervous System, G. Paxinos, ed., Academic Press, San Diego, 1990, pp. 583710.

[31] D. Dougherty and S.L. Rauch, Neuroimaging and neurobiological models of depression, Harvard Review of Psychiatry 5 (1997), 138-159.

[32] W.C. Drevets, Functional neuroimaging studies of depression: the anatomy of melancholia, Annual Review of Medicine 49 (1998), 341-361.

[33] S. Feldman, M.E. Newman, E. Gur and J. Weidenfeld, Role of serotonin in the amygdala in hypothalamo-pituitaryadrenocortical responses, NeuroReport 9 (1998), 20072009.

[34] G.R. Fink, H.J. Markowitsch, M. Reinkemeier, T. Bruckbauer, J. Kessler and W.-D. Heiss, Cerebral representation of one's own past: neural networks involved in autobiographical memory, Journal of Neuroscience 16 (1996), 42754282.

[35] I. Fried, K.A. MacDonald and C.L. Wilson, Single neuron activity in human hippocampus and amygdala during recognition of faces and objects, Neuron 18 (1997), 753-765.

[36] K.J. Friston, Modes or models: a critique on independent component analysis for fMRI, Trends in Cognitive Sciences 2 (1998), 373-375.

[37] K.J. Friston, C.J. Price, P. Fletcher, C. Moore, R.S.J. Frackowiak and R.J. Dolan, The trouble with cognitive subtraction, NeuroImage 4 (1996), 97-104.

[38] T. Furmark, H. Fischer, G. Wik, M. Larsson and M. Fredrikson, The amygdala and individual differences in human fear conditioning, NeuroReport 8 (1997), 3957-3960.

[39] M. Gallagher and A.A. Chiba, The amygdala and emotion, Current Opinion in Neurobiology 6 (1996), 221-227.

[40] J. Grafman, A. Salazar, H. Weingartner, S. Vance and D. Amin, The relationship of brain-tissue loss volume and lesion location to cognitive deficit, Journal of Neuroscience 6 (1986), 301-307.

[41] S.B. Hamann, T.D. Ely, S.T. Grafton and C.D. Kilts, A neuroimaging study of emotion and emotional memory, Journal of Cognitive Neuroscience Suppl. (1999), 19.

[42] S.B. Hamann, T.D. Ely, S.T. Grafton and C.D. Kilts, Amygdala activity related to enhanced memory for pleasant and aversive stimuli, Nature Neuroscience 2 (1999), 289-293.

[43] S.B. Hamann, L. Stefanacci, L.R. Squire, R. Adolphs, D. Tranel, H. Damasio and A. Damasio, Recognizing facial emotion, Nature 379 (1996), 497.

[44] R. Hashimoto, M. Yoshida and Y. Tanaka, Utilization behavior after right thalamic infarction, European Neurology 35 (1995), 58-62.

[45] K. Henke, T. Landis and H.J. Markowitsch, Subliminal perception of pictures in the right hemisphere, Consciousness and Cognition 2 (1993), 225-236.

[46] P.C. Holland and M. Gallagher, Amygdala circuitry in attentional and representational processes, Trends in Cognitive Sciences 3 (1999), 65-73.

[47] S.E. Hyman, Brain neurocircuitry of anxiety and fear: Implications for clinical research and practice, Biological Psychiatry 44 (1998), 1201-1203. 
[48] E. Irle, Lesions size and recovery of function: some new perspectives, Brain Research Reviews 12 (1987), 307-320.

[49] E. Irle and H.J. Markowitsch, Differential effects of prefrontal lesions and combined prefrontal and limbic lesions on subsequent learning performance in the cat, Behavioral Neuroscience 98 (1984), 884-897.

[50] N. Isenberg, D. Silbersweig, A. Engelien, S. Emmerich, K. Malavade, B. Beattie and A.C. Leon, Linguistic threat activates the human amygdala, Proceedings of the National Academy of Sciences of the USA 96 (1999), 10456-10459.

[51] N. Kapur, Paradoxical functional facilitation in brainbehaviour research: a critical review, Brain 119 (1996), 1775-1790.

[52] T.A. Ketter, P.J. Andreason, M.S. George, C. Lee, D.S. Gill, P.L. Parekh, M.W. Willis, P. Herscovitch and R.M. Post, Anterior paralimbic mediation of procaine-induced emotional and psychosensory experiences, Archives of General Psychiatry 53 (1996), 59-69.

[53] A.S. Kling and L.A. Brothers, The amygdala and social behavior, in: The Amygdala: Neurobiological Aspects of Emotion, Memory and Mental Dysfunction, J.P. Aggleton, ed., Wiley-Liss, New York, 1992, pp. 353-377.

[54] H. Klüver and P.C. Bucy, 'Psychic blindness' and other symptoms following bilateral lobectomy in rhesus monkeys, American Journal of Physiology 119 (1937), 352-353.

[55] M. Krickl, U. Poser and H.J. Markowitsch, Interactions between damaged brain hemisphere and mode of presentation on the recognition of faces and figures, Neuropsychologia $\mathbf{2 5}$ (1987), 795-805.

[56] K.S. LaBar, J.C. Gatemby, J.C. Gore, J.E. LeDoux and E.A. Phelps, Human amygdala activation during conditioned fear acquisition and extinction: a mixed-trial fMRI study, $\mathrm{Neu}$ ron 20 (1998), 937-945.

[57] K.S. LaBar, J.E. LeDoux, D.D. Spencer and E.A. Phelps, Impaired fear conditioning following unilateral temporal lobectomy in humans, Journal of Neuroscience 15 (1995), 6846-6855

[58] E. Lanuza, A. Martinez-Marcos and F. Martinez-Garcia, What is the amygdala? A comparative approach, Trends in Neurosciences 22 (1999), 207.

[59] J. LeDoux, The Emotional Brain, Touchstone, New York, 1998.

[60] R. Lilly, J.L. Cummings, D.F. Benson and M. Frankel, The human Klüver-Bucy syndrome, Neurology 33 (1983), 11411145 .

[61] S.J. Lupien and B.S. McEwen, The acute effects of corticosteroids on cognition: integration of animal and human model studies, Brain Research Reviews 24 (1997), 1-27.

[62] H.J. Markowitsch, Which brain regions are critically involved in the retrieval of old episodic memory?, Brain Research Reviews 21 (1995), 117-127.

[63] H.J. Markowitsch, The functional neuroanatomy of episodic memory retrieval, Trends in Neurosciences 20 (1997), 557558.

[64] H.J. Markowitsch, The mnestic block syndrome: Environmentally induced amnesia, Neurology, Psychiatry and Brain Sciences 6 (1998), 73-80.

[65] H.J. Markowitsch, Neuroimaging and mechanisms of brain function in psychiatric disorders, Current Opinions in Psychiatry 12 (1999), 331-337.

[66] H.J. Markowitsch, Functional neuroimaging correlates of functional amnesia, Memory 7 (1999), 561-583.

[67] H.J. Markowitsch, Stress-related memory disorders, in: $C o g$ nitive Neuroscience of Memory, L.G. Nilssonand H.J.
Markowitsch, eds, Hogrefe, Göttingen, 1999, pp. 193-211.

[68] H.J. Markowitsch, Anatomical bases of memory disorders, in: The New Cognitive Neurosciences (2nd ed.), M.S. Gazzaniga, ed., MIT Press, Cambridge, MA, 2000, pp. 781795.

[69] H.J. Markowitsch, Memory and amnesia, in: Principles of Cognitive and Behavioral Neurology, M.-M. Mesulam, ed., Oxford Univ. Press, New York, 2000, pp. 257-293.

[70] H.J. Markowitsch, P. Calabrese, G.R. Fink, H.F. Durwen, J. Kessler, C. Härting, M. König, E.B. Mirzaian, W.-D. Heiss, L. Heuser and W. Gehlen, Impaired episodic memory retrieval in a case of probable psychogenic amnesia, Psychiatry Research: Neuroimaging Section 74 (1997), 119-126.

[71] H.J. Markowitsch, P. Calabrese, M. Würker, H.F. Durwen, J. Kessler, R. Babinsky, D. Brechtelsbauer, L. Heuser and W. Gehlen, The amygdala's contribution to memory - A PETstudy on two patients with Urbach-Wiethe disease, $\mathrm{Neu}$ roReport 5 (1994), 1349-1352.

[72] H.J. Markowitsch, G.R. Fink, A.I.M. Thöne, J. Kessler and W.-D. Heiss, Persistent psychogenic amnesia with a PETproven organic basis, Cognitive Neuropsychiatry 2 (1997), $135-158$.

[73] H.J. Markowitsch, J. Kessler, E. Kalbe and K. Herholz, Functional amnesia and memory consolidation. A case of persistent anterograde amnesia with rapid forgetting following whiplash injury, Neurocase 5 (1999), 189-200.

[74] H.J. Markowitsch, J. Kessler, M.O. Russ, L. Frölich, B. Schneider and K. Maurer, Mnestic block syndrome, Cortex 35 (1999), 219-230.

[75] H.J. Markowitsch, J. Kessler, C. Van der Ven, G. WeberLuxenburger and W.-D. Heiss, Psychic trauma causing grossly reduced brain metabolism and cognitive deterioration, Neuropsychologia 36 (1998), 77-82.

[76] H.J. Markowitsch, J. Kessler, G. Weber-Luxenburger, C. Van der Ven and W.-D. Heiss, Neuroimaging and behavioral correlates of recovery from 'mnestic block syndrome' and other cognitive deteriorations, Neuropsychiatry, Neuropsychology, and Behavioral Neurology 13 (2000), 60-66.

[77] H.J. Markowitsch, M. Reinkemeier, A. Thiel, J. Kessler, A. Koyuncu and W.-D. Heiss, Autobiographical memory activates the right amygdala and temporo-frontal link - A PET study, Acta Neurobiol. Exp. 59 (1999), 219.

[78] H.J. Markowitsch, A. Thiel, J. Kessler and W.-D. Heiss, Ecphorizing semi-conscious episodic information via the right temporopolar cortex - a PET study, Neurocase 3 (1997), 445-449.

[79] A.J. McDonald, Cortical pathways to the mammalian amygdala, Progress in Neurobiology 55 (1998), 257-332.

[80] J.L. McGaugh, Memory - a century of consolidation, Science 287 (2000), 248-251.

[81] J.L. McGaugh, L. Cahill and B. Roozendaal, Involvement of the amygdala in memory storage: interaction with other brain systems, Proceedings of the National Academy of Sciences of the USA 93 (1996), 13508-13514.

[82] M. Mennemeier, E. Fennell, E. Valenstein and K.M. Heilman, Contributions of the left intralaminar and medial thalamic nuclei to memory, Archives of Neurology 49 (1992), 1050-1058.

[83] B.L. Miller, J.L. Cummings, H. McIntyre, G. Ebers and M. Grode, Hypersexuality or altered sexual preference following brain injury, Journal of Neurology, Neurosurgery, and Psychiatry 49 (1986), 867-873.

[84] E. Mori, M. Ikeda, N. Hirono, H. Kitagaki, T. Imanura and T. Shimomura, Amygdalar volume and emotional memory 
in Alzheimer's disease, American Journal of Psychiatry 156 (1999), 216-222.

[85] J.S. Morris, K.J. Friston, C. Büchel, C.D. Frith, A.W. Young, A.J. Calder and R.J. Dolan, A neuromodulatory role for the human amygdala in processing emotional facial expressions, Brain 121 (1998), 47-57.

[86] J.S. Morris, C.D. Frith, D.I. Perrett, D. Rowland, A.W. Young, A.J. Calder and R.J. Doland, A differential neural response in the human amygdala to fearful and happy facial expressions, Nature 383 (1996), 812-815.

[87] J.S. Morris, A. Öhman and R.J. Dolan, Conscious and unconscious emotional learning in the human amygdala, $\mathrm{Na}$ ture 393 (1998), 467-470.

[88] J.S. Morris, A. Öhman and R.J. Dolan, A subcortical pathway to the right amygdala mediating 'unseen' fear, Proceedings of the National Academy of Sciences of the USA 96 (1999), 1680

[89] K. Nader and J.E. LeDoux, Is it time to invoke multiple fear learning systems in the amygdala?, Trends in Cognition Sciences 1 (1997), 241-246.

[90] M.D. Nelson, A.J. Saykin, L.A. Flashman and H.J. Riordan, Hippocampal volume reduction in schizophrenia as assessed by magnetic resonance imaging, Archives of General Psychiatry 55 (1998), 433-440.

[91] J.T. O'Brien, The 'glucocorticoid cascade' hypothesis in man, British Journal of Psychiatry 170 (1997), 199-201.

[92] S. Paradiso, D.L. Johnson, N.C. Andreasen, D.S. O'Leary, G.L. Watkins, L.L. Boles Pont and R.D. Hichwa, Cerebral blood flow changes associated with attribution of emotional valence to pleasant, unpleasant, and neutral visual stimuli in a PET study of normal subjects, American Journal of Psychiatry 156 (1999), 1618-1629.

[93] E.A. Phelps, K.S. LaBar, A.K. Anderson, K.J. O’Connor, R.K. Fulbright and D.D. Spencer, Specifying the contributions of the human amygdala to emotional memory: a case study, Neurocase 4 (1998), 527-540.

[94] M.L. Phillips, A.W. Young, C. Senior, M. Brammer, C. Andrew, A.J. Calder, E.T. Bullmore, D.L. Perrett, D. Row land, S.C.R. Williams, J.A. Gray and A.S. David, A specific neural substrate for perceiving facial expressions of disgust, Nature 389 (1997), 495-498.

[95] A. Pitkänen, Connectivity of the rat amygdaloid complex, in: The Amygdala: A Functional Analysis, J. Aggleton, ed., Oxford Univ. Press, Oxford, 2000, in press.

[96] M.I. Posner and M.E. Raichle, The neuroimaging of human brain function, Proceedings of the National Academy of Sciences of the USA 95 (1998), 763-764.

[97] G.L. Quirarte, B. Roozendaal and J.L. McGaugh, Glucocorticoid enhancement of memory storage involves noradrenergic activation in the basolateral amygdala, Proceedings of the National Academy of Sciences of the USA 94 (1997), 14048-14053.

[98] S.L. Rauch, B.A. van der Kolk, R.E. Fisler, N.M. Alpert, S.P. Orr, C.R. Savage, A.J. Fischman, M.A. Jenike and R.K. Pitman, A symptom provocation study of posttraumatic stress disorder using positron emission tomography and scriptdriven imagery, Archives of General Psychiatry 53 (1996), 380-387.

[99] M.T. Rogan, U.V. Stäubli and J.E. LeDoux, Fear conditioning induces associative long-term potentiation in the amygdala, Nature 390 (1997), 604-607.

[100] E.T. Rolls, Neurophysiology and functions of the primate amygdala, in: The Amygdala: Neurobiological Aspects of
Emotion, Memory and Mental Dysfunction, J.P. Aggleton, ed., Wiley-Liss, New York, 1992, pp. 143-165.

[101] B. Roozendaal, G. Portillo-Marquez and J.L. McGaugh, Basolateral amygdala lesions block glucocorticoid-induced modulation of memory for spatial learning, Behavioral Neuroscience 110 (1996), 1074-1083.

[102] J.A. Salinas, M.B. Parent and J.L. McGaugh, Ibotenic acid lesions of the amygdala basolateral complex or central nucleus differentially effect the response to reductions in reward, Brain Research 742 (1996), 283-293.

[103] R.M. Sapolsky, Stress, glucocorticoids, and damage to the nervous system: The current state of confusion, Stress 1 (1996), 1-19.

[104] M. Sarter and H.J. Markowitsch, The involvement of the amygdala in learning and memory: A critical review with emphasis on anatomical relations, Behavioral Neuroscience 99 (1985), 342-380.

[105] S. Scarone, C. Colombo, S. Livian, M. Abbruzzese, P. Ronchi, M. Locatelli, G. Scotti and E. Smeraldi, Increased right caudate nucleus size in obsessive-compulsive disorder: Detection with magnetic resonance imaging, Psychiatry Research: Neuroimaging 45 (1992), 115-121.

[106] F. Schneider, W. Grodd, U. Weiss, U. Klose, K.R. Mayer, T. Nägele and R.C. Gur, Functional MRI reveals left amygdala activation during emotion, Psychiatry Research: Neuroimaging 76 (1997), 75-82.

[107] F. Schneider, R.E. Gur, L.H. Mozley, R.J. Smith, P.D. Mozley, D.M. Censits, A. Alavi and R.C. Gur, Mood effects on limbic blood flow correlate with emotional self-rating: A PET study with oxygen-15 labeled water, Psychiatry Research: Neuroimaging 61 (1995), 265-283.

[108] F. Schneider, U. Weiss, C. Kessler, J.B. Salloum, S. Posse, W. Grodd, W. and H.W. Müller-Gärtner, Differential amygdala activation in schizophrenia during sadness, Schizophrenia Research 34 (1998), 133-142.

[109] G. Schoenbaum, A. Chiba and M. Gallagher, Orbitofrontal cortex and basolateral amygdala encode expected outcomes during learning, Nature Neuroscience 1 (1998), 155-159.

[110] M. Seeck, N. Mainwaring, J. Ives, H. Blume, D. Dubuisson, R. Cosgrove, M.M. Mesulam and D.L. Schomer, Differential neural activity in the human temporal lobe evoked by faces of family members and friends, Annals of Neurology 34 (1993), 369-372.

[111] Y.L. Sheline, M.H. Gado and J.L. Price, Amygdala core nuclei volumes are decreased in recurrent major depression, NeuroReport 9 (1998), 2023-2028.

[112] K.S. Sims and R.S. Williams, The human amygdaloid complex: a cytologic and histochemical atlas using Nissl, myelin, acetylcholinesterase and nictotinamide adenine dinucleotide phosphate diaphorase staining, Neuroscience 36 (1990), 449-472.

[113] J.M. Sprague, Interaction of cortex and superior colliculus in mediation of visually guided behavior in the cat, Science $\mathbf{1 5 3}$ (1966), 1544-1547.

[114] R. Sprengelmeyer, M. Rausch, U.T. Eysel and H. Przuntek, Neural structures associated with recognition of facial expressions of basic emotions, Proceedings of the Royal Society of London 265 (1998), 1927-1931.

[115] V.E. Stone, The role of the frontal lobes and the amygdala in theory of mind, in: Understanding Other Minds: Perspectives from Autism and Developmental Cognitive Neuroscience (2nd ed.), S. Baron-Cohen, H. Tager-Flusberg and D.J. Cohen, eds, Oxford University Press, New York, 1999, in press. 
[116] L.W. Swanson and G.D. Petrovich, What is the amygdala?, Trends in Neurosciences 21 (1998), 323-331.

[117] J.D. Teasdale, R.J. Howard, S.G. Cox, Y. Ha, M.J. Brammer, S.C.R. Williams and S.A. Checkley, Functional MRI study of the cognitive generation of affect, American Journal of Psychiatry 156 (1999), 209-215.

[118] G. Tononi, A.R. McIntosh, D.P. Russell and G.M. Edelman, Functional clustering: Identifying strongly interactive brain regions in neuroimaging data, Neuroimage 7 (1998), 133149.

[119] D. Tranel, Emotional processing and the human amygdala, Trends in Cognitive Sciences 1 (1997), 46-48.

[120] E. Tulving, Elements of episodic memory, Oxford University Press, Oxford, 1983.

[121] Y.D. Van der Werf, J.G.E. Weerts, J. Jolles, M.P. Witter, J. Lindeboom and P. Scheltens, Neuropsychological correlates of a right unilateral lacunar thalamic infarction, Journal of Neurology, Neurosurgery, and Psychiatry 66 (1999), 36-42.

[122] A. Vazdarjanova and J.L. McGaugh, Basolateral amygdala is not critical for cognitive memory of contextual fear conditioning, Proceedings of the National Academy of Sciences of the USA 95 (1998), 15003-15007.

[123] P. Vuilleumier, F. Ghika-Schmid, J. Bogousslavsky, F. Assal and F. Regli, Persistent recurrence of hypomania and prosopoaffective agnosia in a patient with right thalamic infarct, Neuropsychiatry, Neuropsychology and Behavioral Neurology 11 (1998), 40-44.

[124] D.L. Walker and M. Davis, Double dissociation between the involvement of the bed nucleus of the stria terminalis and the central nucleus of the amygdala in startle increases produced by conditioned versus unconditioned fear, Journal of Neuroscience 17 (1997), 9375-9383.

[125] A.F. Wechsler, The effect of organic brain disease on recall of emotionally charged versus neutral narrative texts, Neurology 23 (1973), 130-135.

[126] G. Weniger, E. Irle, C. Exner and E. Rüther, Defective conceptualization of emotional facial expressions during T2 signal enhancement of the right amygdala, Neurocase 3 (1997), 259-266.

[127] C. Wernicke, Der aphasische Symptomenkomplex, Cohn \& Weigert, Breslau, 1874.

[128] P.J. Whalen, S.L. Rauch, N.L. Etcoff, S.C. McInerney, M.B. Lee and M.A. Jenike, Masked presentations of emotional facial expressions modulate amygdala activity without explicit knowledge, Journal of Neuroscience 18 (1998), 411-418.

[129] M. Worden and W. Schneider, Cognitive task design for fMRI, International Journal of Imaging Systems and Technology 6 (1995), 253-270.

[130] A.W. Young and J.P. Aggleton, Emotional processing and the human amygdala. (Response to Tranel), Trends in Cognitive Sciences 1 (1997), 47-48.

[131] D.H. Zald and J.V. Pardo, Emotion, olfaction, and the human amygdala: Amygdala activation during aversive olfactory stimulation, Proceedings of the National Academy of Sciences of the USA 94 (1997), 4119-4124. 


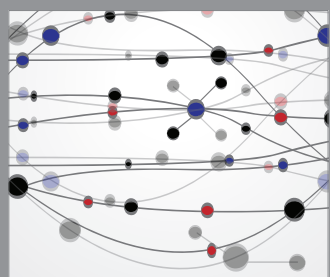

The Scientific World Journal
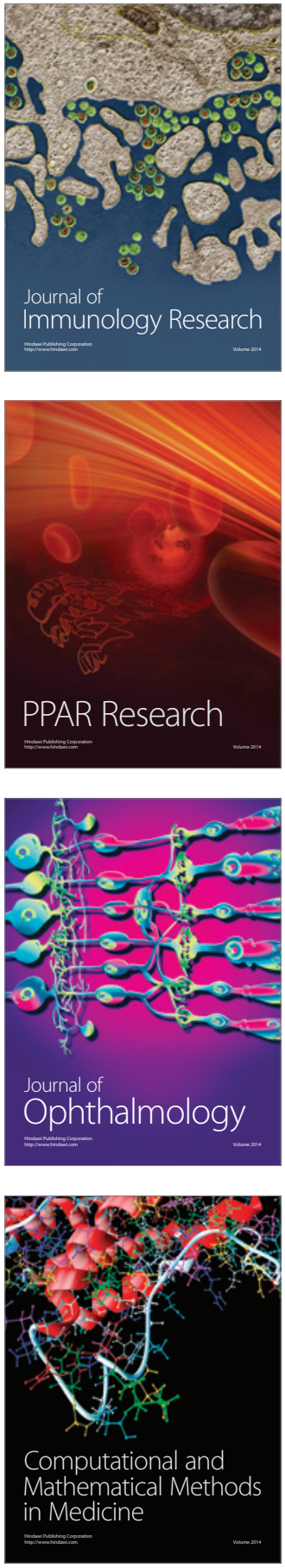

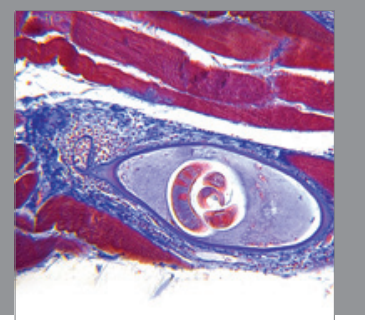

Gastroenterology

Research and Practice
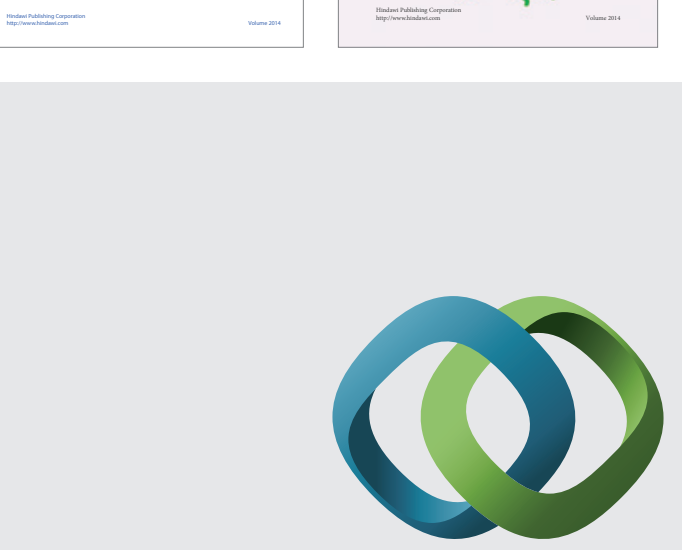

\section{Hindawi}

Submit your manuscripts at

http://www.hindawi.com
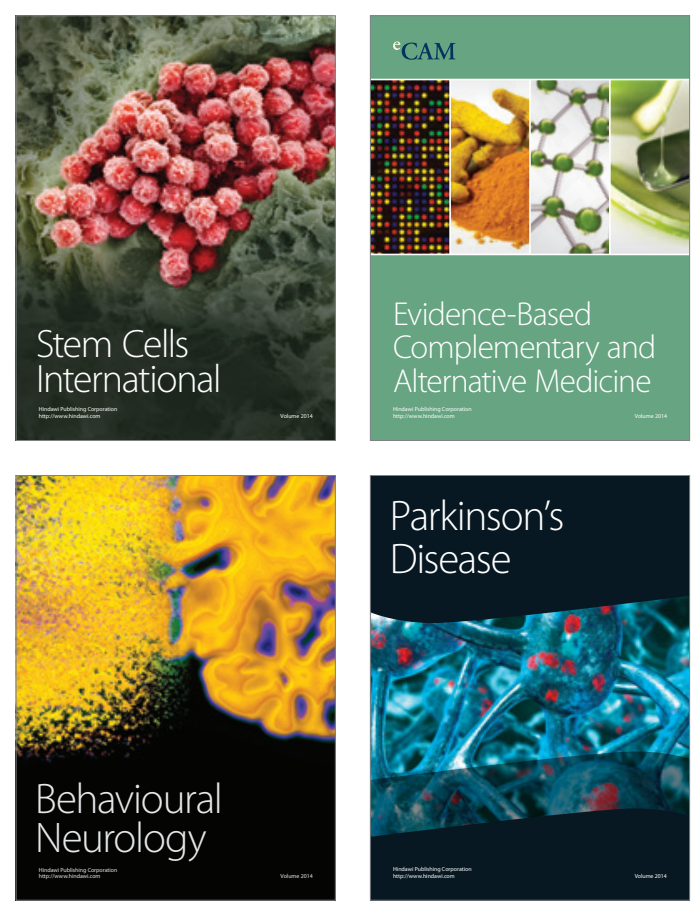

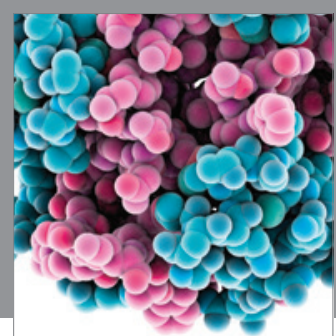

Journal of
Diabetes Research

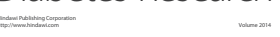

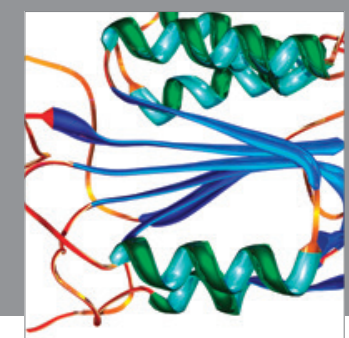

Disease Markers
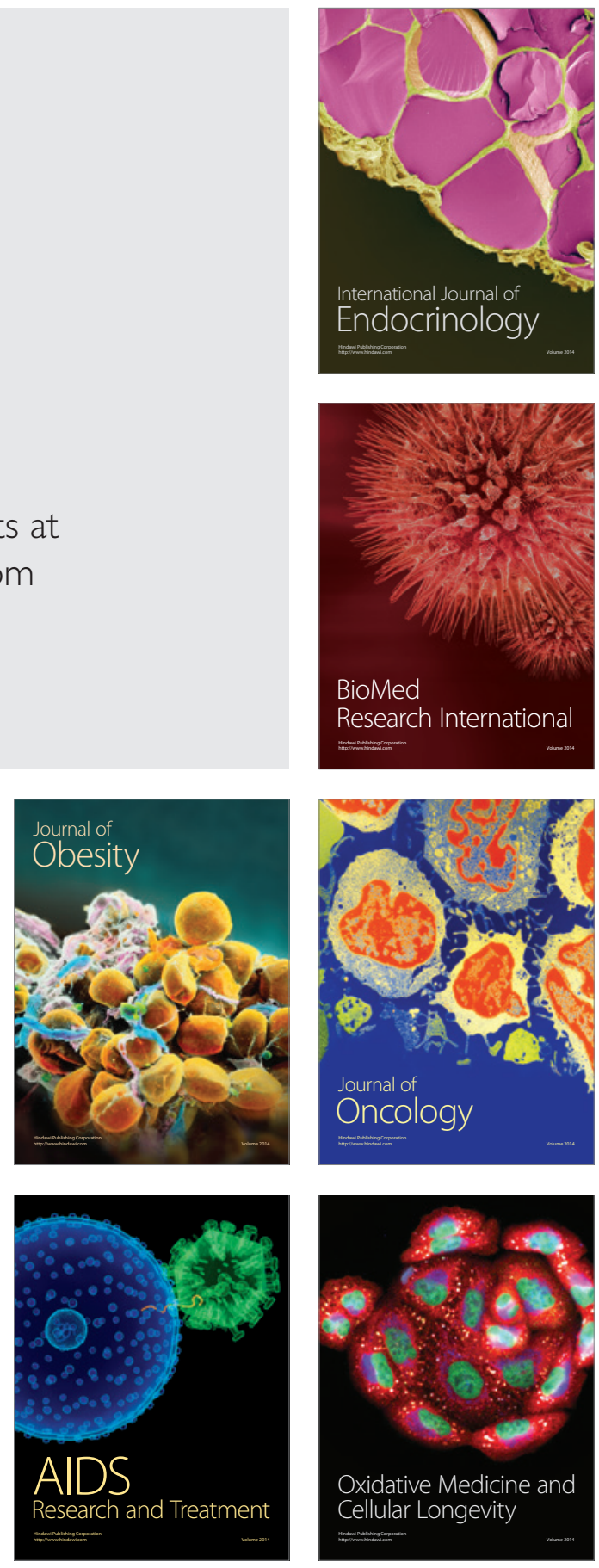